\title{
A Feasibility Study on Applying Remotely Sensed data for Agricultural Management in Beyza Land
}

\author{
S. Abbas Montaseri \\ Computer Engineering Department \\ Beyza Branch, Islamic Azad University, \\ Fars, Iran
}

\author{
Reza Javidan \\ Computer Engineering Department \\ Beyza Branch, Islamic Azad University, \\ Fars, Iran
}

\begin{abstract}
Today, because of increasing demands for agricultural products and existence of restrictions against resources such as lack of natural water resources for producing agricultural products using traditional methods, it is a need to use modern techniques such as satellite remote sensing to manage natural resources. The need for agriculture is to increase the production by optimum utilization of resources. Remote sensing satellites could be a good option for water and nutrient requirement and disease detection. In this paper a feasibility study is carried out for using remote sensing images for managing agricultural resources in the area of Beyza, a land in Fars province in Iran. After a study on availability of different imagery resources covered this area and the way of accessing such data in a good manner, ETM+ of Landsat satellite is selected as the source of data. After that the image processing steps required for extracting useful information are discussed and finally a practical model is proposed that should be implemented for applying the model on the real condition. The simulation results based on prototype data and previous studies showed the effectiveness of the proposed model.
\end{abstract}

\section{Keywords}

Remote sensing, agriculture, management, Beyza land, image, feasibility study, model

\section{INTRODUCTION}

With increasing population in the world and the need for increased agricultural production, there is a need for optimized management of the world's agricultural resources. To do this, it is necessary to acquire reliable data on the types of resources and the quality, quantity and location of these resources. As a result, satellite remote sensing technologies became as important tools for improving the present systems of acquiring and generating agricultural and natural resource data.

Today remote sensing techniques have many applications in natural resource management such as mining, urban monitoring, fire detection, flood prediction and precision agricultural management. Precision agriculture will change the way of traditional farming and it offers a numerous of benefits in cost-effectiveness, productivity, sustainability, quality of crops, environmental protection, food safety and country economic development. There are many new international standard approaches which target to increase the efficiency of used resources and to decrease the ambiguity of decisions required to manage changeability on agricultural farms [1].

Remote sensing techniques allow non-destructive acquisition of information about the Earth's surface and they may assist the implementation of precision agriculture. These executions can be summarized in three main stages: (1) Gathering information using satellite imageries (2) Processing and analyzing information to assess the significance of changeability and (3) Producing relevant outputs in forms of maps and other useful databases.

Remote sensing today play an important role in estimating crop condition and profit forecasting, domain estimates of specific crops, detection of crop pests and diseases, finding disaster location, monitoring wild life, gathering water supply information, weather forecasting, management of lands, and livestock studies [2].

In this paper a feasibility study is carried out for using remote sensing images for managing agricultural resources in the area of Beyza, a land in Fars province in Iran. After a study on availability of different imagery resources covered this area and the way of accessing such data in a good manner, the image processing steps required for extracting useful information are discussed and finally a practical model is proposed. It is also focused on the previous studies that was performed in Iran in different parts and used these experiences for proposing the model.

The rest of this paper is organized as follows: in Section 2 a short review about the fundamental of remote sensing is described. Some related works are explained in Section 3. Our feasibility study and discussion is the subject of Section 4. Finally conclusion and remarks are outlined in Section 5.

\section{REMOTE SENSING}

Remote sensing is the science and art of obtaining information about an object, area, or phenomenon through the analysis of data acquired by a device that is not in contact with the object, area, or phenomenon under investigation. The remotely collected data can be of many forms including electromagnetic energy distribution [3].

Figure 1 illustrates the generalized process involved in electromagnetic remote sensing of earth resources. A remote sensing system using electromagnetic radiation has four components [4]:

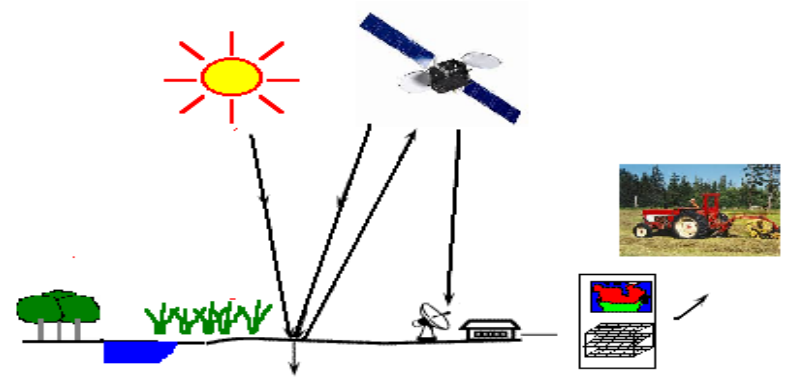

Figure 1 - Earth remote sensing fundamentals 
1- Source: the source of electromagnetic radiation may be natural like the Sun's reflected light or manmade like microwaves radar.

2- Earth's surface interaction: the amount of radiation reflected from the earth surface is depends on the characteristic of objects on the earth's surface.

3- Atmospheric interaction: Electromagnetic energy passing through the atmosphere is distorted and scattered.

Sensors on the remote sensing satellites are categorized into two main groups: passive and active. Passive sensors gather natural radiation that is emitted or reflected by the object or surrounding areas. Active systems, on the other hand, emit energy in order to scan objects and areas whereupon a sensor then detects and measures the radiation that is reflected or backscattered from the target. RADAR and LiDAR are examples of active remote sensing where the time delay between emission and return is measured, establishing the location, speed and direction of an object.

Resolution is a measure of the ability of an optical system to distinguish between signals that are spatially near or spectrally similar. On the other hand, the quality of remote sensing data consists of its spatial, spectral, radiometric and temporal resolutions. These four types of resolutions are described as follows:

Spectral resolution: it refers to the dimension and the number of specific wavelength intervals in the electromagnetic spectrum to which sensor is sensitive.

Spatial resolution: is a measure of the smallest angular or linear separation between two objects that can be resolved by the sensor.

Temporal resolution: refers to how often a given sensor obtain image of a particular area.

Radiometric resolution: defines the sensitivity of a detector to differences in signal strength as it records the radiant flux reflected or emitted from the terrain.

\section{RELATED WORKS}

The use of remotely sensed data is being investigated all over the world for crop production forecasting. Remote Sensing can provide good information on crop growth on a regional scale indicate the crop growth and potential grain yield. The estimation using remote sensing data has been demonstrated in various parts of the world. However, yield prediction is a subject of intensive research and is still at a developmental stage.

In [5], urban region growing in Amol, a city of northern area of Iran is carried on by using aerial photograph and KFA1000 stereo data over 20 years. She used a simple and fats method to do the work. The results indicate that remote sensing techniques can be used to access very rapidly the growth of urban areas which is very easy in developing countries.

In [2], they highlight the experience of development of satellite-based methodology, results and achievements of wheat production forecasting in Haryana state of India under the project since 1989-90.

In [6], they used hyperspectral data for agricultural crop stress detection. In this study they considered the nutrient stress, disease stress and water stress of potato corps.

A good review of applications of remote sensing on precision agriculture is outlined in [1]
Preparing the land map of agricultural farms of Gilan province in Iran is another work that was done [7]. They used of IRS, ETM and LISSIII with different resolutions to provide a good maps from agricultural farms and jungles as well as civilian parts of the province. Figure 2 shows the results of this study.

In [7] a wheat map in Ghazvin province in Iran was prepared using satellite imageries. In this study the ETM images of Landsat satellite are used and the final result is outlined in Figure 3.

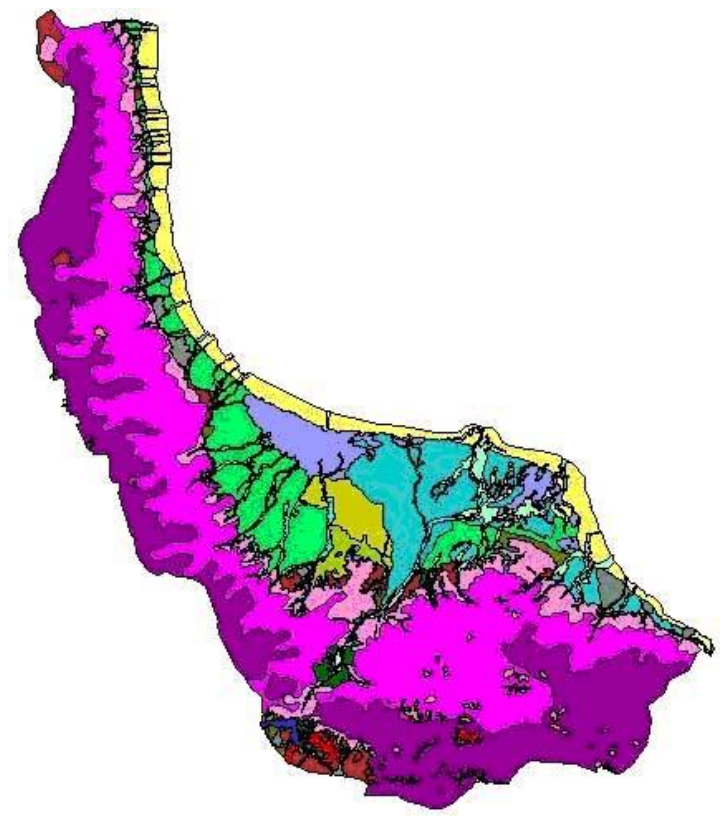

Figure 2 - The land farms of Gilan province in Iran [7]

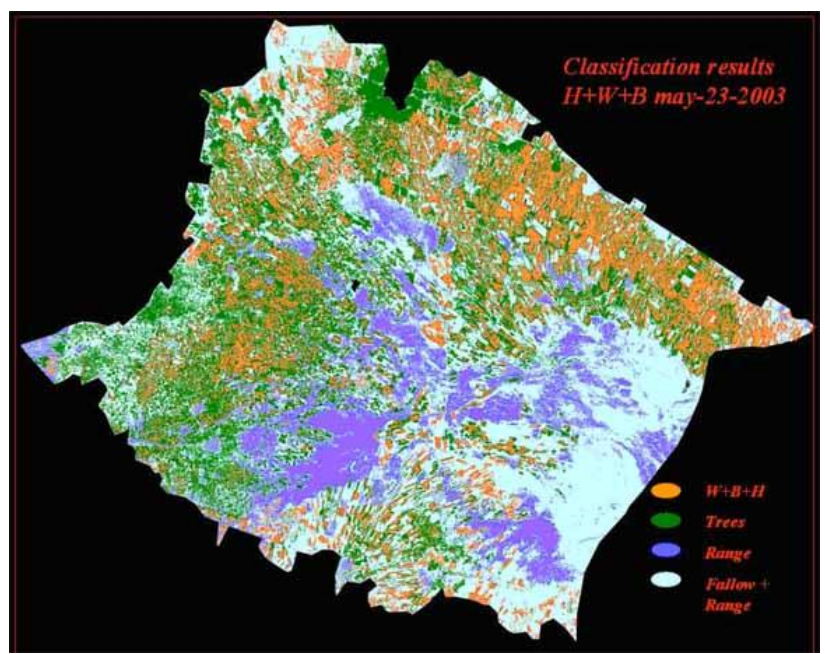

Figure 3 - The wheat land farms of Ghazvin province in Iran [7]

\section{METHOD AND PROCEDURE}

\subsection{The area under study}

Beyza is situated in Fars, Iran with average elevation: 1606 meters. Its geographical coordinates are: Latitude: $29^{\circ} 58^{\prime}$ 10.9194", Longitude : $52^{\circ} 24^{\prime} 3.5274$. This place is a covered 


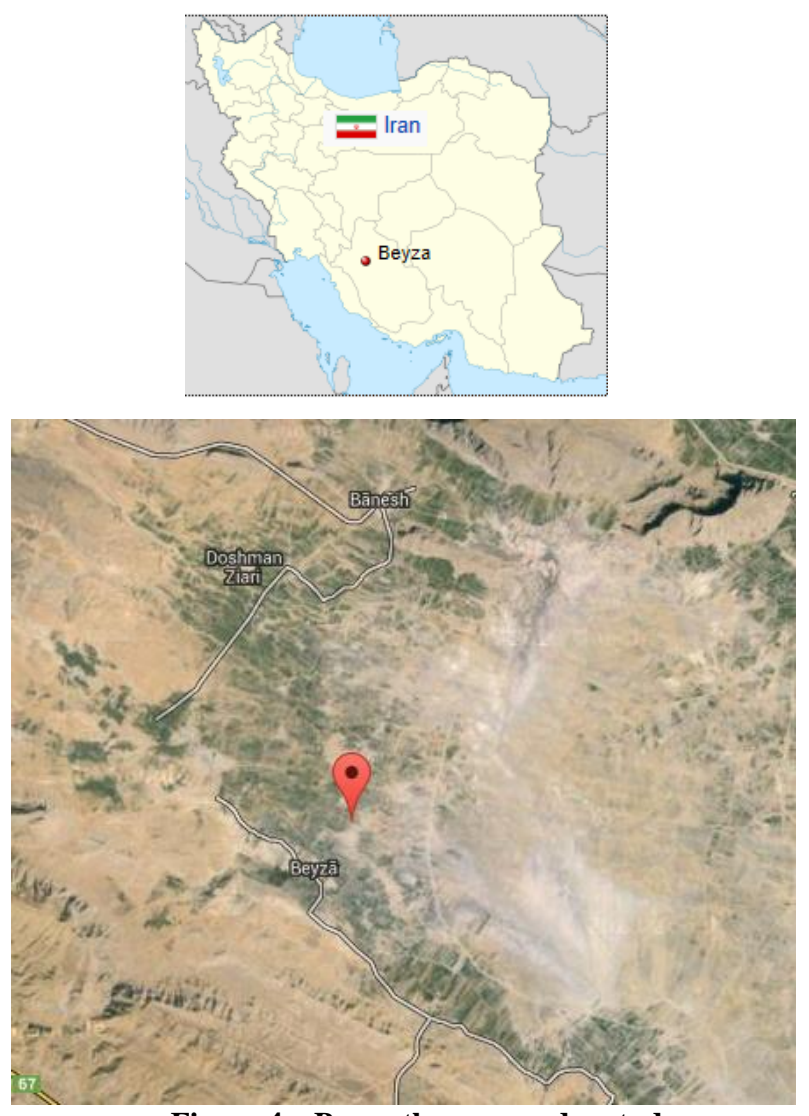

Figure 4 - Beyza the area under study

with many corps and small farms and it is evaluated to be one of the important places for farming in Fars province in Iran. Figure 4 shows the region under study. The main water resources in this area are supplied from deep wells and there is not any river of dam for agricultural purposes in this area. The most important products in this area are: wheat, grain, grape, apple and greens.

Since this place is an important area for vegetation and other farming purposes, we focused on the management of agricultural plans using satellite images data.

\subsection{Satellite data}

We carried on very wide studies on available images from different satellites which cover this land. We focused on two main objectives. The first one was the availability of data in Iran. The second one was the existence of previous experience for agricultural purposes. Landsat, IRS, Spot satellites cover Iran which should be bought. In addition, NOAA, TERRA, IRS-1C, and Chinese FY2C satellites have receiving stations in Iran. This study was carried out on these data types.

Indian IRS series of earth observation satellites data should be bought in one hand, and the IRS-1C which has the receiving antenna in Iran is not operational for future observation and its data is obsolete. In addition the quality of data is less than images acquired from SOPT satellites, for example.

SPOT, French satellite for observation of Earth has commercial high-resolution optical images. At the time of this study, SPOT 5, 6, 7 are operational. SPOT 5 launched May 4, 2002 with $2.5 \mathrm{~m}, 5 \mathrm{~m}$ and $10 \mathrm{~m}$ capability. However, based on previous studies in agricultural management, less works was carried out on these images. As a result in the presented work Landsat satellite data series was selected based on the existing experiences reported by previous works (see Section 2).
Table 1- Landsat 7 ETM+ imagery specifications [8]

\begin{tabular}{|c|c|c|c|}
\hline Satellite & $\begin{array}{c}\text { Spectral } \\
\text { Resolution }(\mu)\end{array}$ & Band & \begin{tabular}{|c|} 
Spatial Resolution \\
$(\mathrm{m})$
\end{tabular} \\
\hline \multirow{10}{*}{ 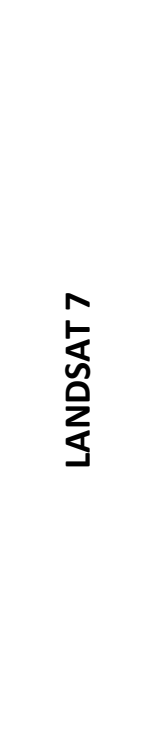 } & \multicolumn{3}{|c|}{ ETM+ } \\
\hline & $\begin{array}{l}\text { Band 1: } 0.450- \\
\quad 0.515\end{array}$ & Blue & $\begin{array}{l}28.50 \text { Meter } \\
\text { Resolution }\end{array}$ \\
\hline & $\begin{array}{l}\text { Band 2: } 0.525- \\
\quad 0.605\end{array}$ & Green & $\begin{array}{l}28.50 \text { Meter } \\
\text { Resolution }\end{array}$ \\
\hline & $\begin{array}{l}\text { Band 3: } 0.630- \\
\quad 0.690\end{array}$ & Red & $\begin{array}{l}\text { 28.50 Meter } \\
\text { Resolution }\end{array}$ \\
\hline & $\begin{array}{l}\text { Band 4: } 0.760- \\
\quad 0.900\end{array}$ & Near IR & $\begin{array}{l}\text { 28.50 Meter } \\
\text { Resolution }\end{array}$ \\
\hline & $\begin{array}{l}\text { Band 5: } 1.550- \\
\quad 1.750\end{array}$ & Mid IR & $\begin{array}{l}28.50 \text { Meter } \\
\text { Resolution }\end{array}$ \\
\hline & $\begin{array}{l}\text { Band 6: } 10.40- \\
12.5\end{array}$ & Thermal & $\begin{array}{l}\text { 57.00 Meter } \\
\text { Resolution }\end{array}$ \\
\hline & $\begin{array}{l}\text { Band 7: } 2.080- \\
\quad 2.35\end{array}$ & Far IR & $\begin{array}{l}28.50 \text { Meter } \\
\text { Resolution }\end{array}$ \\
\hline & \multicolumn{3}{|c|}{ Panchromatic } \\
\hline & Band 8: $0.52-0.92$ & Pan & $\begin{array}{l}\text { 14.25 Meter } \\
\text { Resolution }\end{array}$ \\
\hline \multicolumn{4}{|c|}{$\begin{array}{l}\text { * Note: Band } 6 \text { on LANDSAT } 7 \text { is divided into two bands, high } \\
\text { and low gain. }\end{array}$} \\
\hline
\end{tabular}

The Landsat satellite series as the longest project for acquisition of satellite imagery of Earth since 1972 produces the largest data source for remote sensing. The most recent, Landsat 8 was launched on February 11, 2013. These archived data are a unique resource for global change research and applications in agriculture, cartography, geology, forestry, regional planning, and surveillance.

Landsat 7 data has eight spectral bands with spatial resolutions ranging from 15 to 60 meters; the temporal resolution is 16 days. There are many researches carried out in Iran and other parts of the world for agricultural assessment based on these data. For such reasons and based on the quality of the images with vegetation and farming application, Landsat 7 ETM+ imageries are selected as the first selection in this project. Table 1 shows the specification of this type of satellite images.

\subsection{Image processing and interpretation}

In remote sensing while the object of interest is not directly measured, there exists some other variable that can be measured which may be related to the object of interest through the use of a data-derived computer model.

From acquisition to the final product delivered to the user, a remotely sensed image goes through a series of image processing steps [9]:

Image Coding: improvement on quality leads to an increasing demand on storage and bandwidth transmission capabilities. Image coding and compression techniques have been used in hyperspectral images. In this step the decoding process is necessary.

- Atmospheric Corrections: Solar radiation reflected by the Earth's surface to satellite sensors is modified by its interaction with the atmosphere. The objective of applying an atmospheric correction is to determine true surface reflectance values and to retrieve physical parameters of the Earth's surface, including surface reflectance, by removing atmospheric effects from satellite images [10]. 
Feature Extraction: Because of high dimensional datasets and increasing in computational time feature extraction is used to reduce the dimensionality. Filters and wrappers, which guarantee that the selected feature subset is iteratively optimized, are used.

Image Restoration and Enhancement: Image restoration is an important step including noise removal and scattered either in the spatial or specific spectral bands correction. In addition, image enhancement will improve the visual quality of the images.

Data Fusion: Since the design of a high resolution sensor in both spectral and spatial domains would be extremely costly and challenging in terms of engineering, image fusion methods are often employed to create an image taking advantage of both.

- Image Modeling and Classification: The use of empirical, parametric, nonparametric and nonlinear models is used to learn the relationship between the acquired spectra and actual ground measurements. In addition, Classification maps as the main product of image processing, is used to classify the final data. Supervised and unsupervised are two main categories in this section.

Remote sensing data is processed and analyzed with computer software, known as a remote sensing application. Another criteria that should be evaluated is the availability of computer software tools for collaborating in our projects.

A large number of proprietary and open source applications exist to process remote sensing data. Some of remote sensing software packages include: Socet GXP from BAE Systems, TNTmips from Microlmages, PCI Geomatica from PCI Geomatics, IDRISI from Clark Labs, Image Analyst from Intergraph, RemoteView made by Overwatch Textron Systems and Dragon/ips as one of the oldest remote sensing packages. Open source remote sensing softwares includes: Opticks and Orfeo toolbox. Others mixing remote sensing and GIS capabilities are: GRASS GIS, ILWIS, QGIS, and TerraLook.

In addition, In Iran, Arc/View Image Analysis, ERDAS IMAGINE, ERMAPPER, Imagine Essentials, 3D Mapper, Orthoengine and Smart Image are the most software tools that are used for remotely sensed image analysis and land map production. As a result, in our assessment we have no problem for using image processing tools [11].

\subsection{Vegetation Index for Beyza Land}

In this study, Normalized Difference Vegetation Index (NDVI) which has extensive applications in vegetative management is selected for estimating crop yields and vegetation management. It is a numerical index that uses the visible and near-infrared bands of the electromagnetic spectrum.

Generally, healthy vegetation will absorb most of the visible light that falls on it, and reflects a large portion of the nearinfrared light. Unhealthy or sparse vegetation reflects more visible light and less near-infrared light. Bare soils on the other hand reflect moderately in both the red and infrared portion of the electromagnetic spectrum. Therefore, the bigger the difference between near-infrared and red reflectance, the more vegetation there has to be. Theoretically, NDVI values are represented as a ratio ranging in value from -1 to 1 but in practice extreme negative values represent water, values around zero represent bare soil and values over 6 represent dense green vegetation.
For our study, the most important task is to retrieve the true values of the vegetation status from the satellite remotely sensed data. Any omission of considering the effects of the atmosphere when vegetation indices from satellite images are used, may lead to major discrepancies in the final outcomes. In this sense, atmospheric correction is the most important part of the pre-processing of satellite remotely sensed data since influence the final results. Such a correction is especially important in cases where multi-temporal images are to be compared and analyzed. For agricultural applications, in which several vegetation indices are applied for monitoring purposes, multi-temporal images are used. The integration of vegetation indices from remotely sensed images with other hydrometeorological data is widely used for monitoring natural hazards such as droughts [10].

\subsection{A Model for Beyza Land}

Beyza land is a covered with many corps and small farms and it is evaluated to be one of the important places for farming in Fars province in Iran. After a feasibility study on applying remote sensing techniques for managing agricultural resources in this area, a conceptual model is presented to apply practically this study in the future. Figure 3 shows this model. At first step, ETM+ Landsat imageries from the area under study from past to present should be prepared. Using these data, the image processing steps are implemented: image coding, atmospheric correction, feature extraction, image restoration and image enhancement, data fusion and image modeling and classification. Finally based on the result change analysis stage is carried out to understand the changes happened in compare with previous temporal data. New maps are produce and based on the final result the new plan for agricultural management will perform.

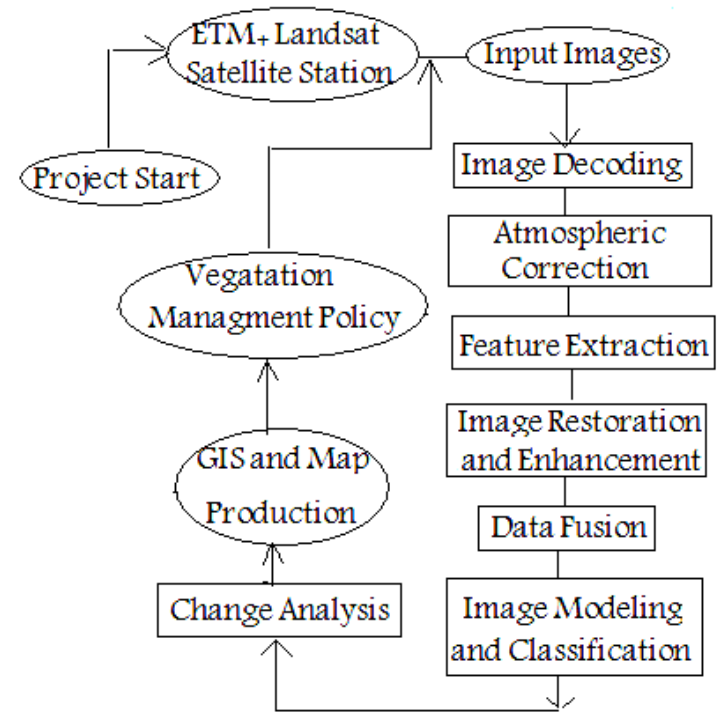

Figure 5 - A Conceptual model for Beyza land to apply remote sensing

\section{CONCLUSION}

Increasing demand for agricultural products from one side and lack of water resources for producing agricultural products using traditional methods on the other hand causes to use modern techniques such as satellite remote sensing to manage natural resources. In this paper a feasibility study was carried out for using remote sensing images for managing agricultural resources in the area of Beyza, a land in Fars province in Iran. After a study on availability of different imagery resources 
covered this area and the way of accessing such data in a good manner, the image processing steps required for extracting useful information were discussed and finally a practical mode is proposed. It is concluded that using ETM+ Landsat imageries which covers the area under study and the NDVI vegetation index and the process of image processing, modern remote sensing techniques can be applied for the management of crops and farms in Beyza land.

\section{REFERENCES}

[1] Liaghat S. and Balasundram S.K.. 2010. A Review: The Role of Remote Sensing in Precision Agriculture. American Journal of Agricultural and Biological Sciences 5 (1): 50-55.

[2] Hooda R.S., Yadav Manoj and Kalubarme M. H.. Wheat Production Estimetion Using Remote Sensing Data: an Indian Experience. In Proceedings of Workshop on Remote sensing support to crop yield forecast and area estimates.

[3] Barzegar F. and Farrokhi Sh.. 1995. Remote Sensing and its Applcations in Oceanography and Marine resources. Iranian National Cententer for Oceanography (INCO).

[4] Curran Paul J.. 1995. Principels of Remote Sensing, Longman scientific \& Technical.

[5] Lotfi Sedigeh. 2001. Remote Sensing for Urban Growth in Northern Iran. In Proceeding of 22th Asian Conference on Remote Sensing, 5-9 Nov, Singapore.
[6] Ray Shbendu Shankar, Singh J. P. and a Panigrahy Sushm. 2010. Use of Hyperspectral Remote Sensing Data for Crop Stress Detection: Ground-Based Studies. International Archives of Photogrammetry, Remote Sensing and Spatial Information Science, Vol. xxxviii, Part 8, Japan.

[7] Iranian Space Agency Website: http://www.isa.ir [accessed September 2012].

[8] http://landsat.usgs.gov [accessed June 2014]

[9] Tuia Devis and Camps-Valls Gustavo. 2009. Recent advances in remote sensing image processing. In Proceedings of the 16th IEEE international conference on Image processing, November 07-10, Cairo, EgyptBowman

[10] Hadjimitsis D.G., Papadavid G., Agapiou A., Themistocleou K., Hadjimitsis M.G., Retalis A., Michaelides S., Chrysoulakis N., Toulios L. and Clayton C.R.I. 2010. Atmospheric correction for satellite remotely sensed data intended for agricultural applications: impact on vegetation indices. Nat. Hazards Earth Syst. Sci., 10, 89-95.

[11] Montaseri S.A. and javidan Reza. 2012. A Feasibility Study on Applying Remotely Sensed data for Agricultural Management in Beyza Land. A Technical Report, Beyza Branch, Islamic Azad University. 